\title{
UNA LECTURA DE LA HISTORIA DEL \\ PARAGUAY DESDE LA \\ INTERTEXTUALIDAD
}

\author{
Mónica Marinone ${ }^{*}$
}

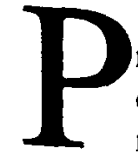

rivilegiar la instancia de la lectura ${ }^{\prime}$ en La revolución en bicicleta, de Mempo Giardinelli ${ }^{2}$ implica tener presentes alternativas diversas respecto de quien se desplaza por el texto: que no perciba la posibilidad de vincularlo con otro anterior de la serie literaria constituida por textos ficcionales de temática paraguaya, asimismo que se enfrente con el relato de acontecimientos histórico-sociales desarrollados en Paraguay que quizás no forman parte de su enciclopedia ${ }^{3}$, pero que no obstante, disfrute de su comicidad y frescura. También es posible que la lectura origine esto último y además el reconocimiento, sino del tiempo-espacio ficcionalizado, por lo menos de elementos que permitan apropiarse con $\mathrm{La}$ revolución... de otro texto-signo anterior. Nos interesa esta última alternativa, pues a partir de ella se crea un espacio que instala y continúa una

*Universidad Nacional de Mar del Plata - Argentina

esenci Fundamento esta propuesta en los planteos teóricos que consideran al lector como polo esencial en el proceso de producción de sentido de todo fenómeno literario (W Iser, El acto de leer. Madrid: Tauros, 1987 y J Lotman, Estructura del texto artístico. Madrid: Istmo, 1982).

As.: Bruguera, 1984.

3 U. Eco, Lector in fabula. Espania: Lumen, 1981. 
re-lectura de la historia del Paraguay desde un proceso intertextual que re-envia a Hijo de hombre, de A. Roa Bastos ${ }^{4}$ y simultáneamente al sistema cultural en el cual la escritura ha sido gestada. 5

En Hijo de hombre el lector circula por hechos acontecidos en ese pais durante un cuarto de siglo, contactándose especialmente con la ficcionalización de la guerra del Chaco (1932-1935) y se planta, desde la referencia de algunos personajes, en un tiempo que se ahonda en el pasado hasta llegar a cuatro siglos atrás, con la alusión a la época de las Misiones Jesuiticas, en el ámbito guarani. La revolución en bicicleta, por su parte, recupera a partir de la narración de Bartolo Gaite, ex-oficial del ejército paraguayo exiliado en el Chaco, la visión de un país diezmado por la guerra de la Triple Alianza (1865-1870) y permite avanzar, desde el transcurrir de la lectura, hasta la época de la dictadura de Alfredo Stroessner, concentrándose en el acontecimiento que aparece como soporte del texto: el levantamiento civico-militar de 1947 contra el dictador Higinio Morínigo, general que asume el poder después de muerto José Félix Estigarribia, promocionado héroe del Chaco.

Ambas ficciones condensan o refieren problemáticas emergentes de procesos históricos recurrentes en Paraguay: el trabajo-castigo en los yerbales, la marginación social, las consecuencias de las guerras y especialmente los enfrentamientos entre militares y civiles, de modo tal que se motiva no sólo el acceso al pasado, sino también el acercamiento al presente. La revolución en bicicleta parodiza ${ }^{6}$ la organización fragmentaria de Hijo de hombre: es posible observar en nuestro tex to tres partes y un epilogo. Tanto los capitulos impares de las partes primera y tercera como el epílogo, introducen el presente de Bartolo Gaite, articulado desde una tercera persona, que comprende un breve extensión temporal-desde la mañana a la noche de un mismo dia. El lineamiento de los capítulos pares de las partes

4 ARoa Bastos, Hijo de hombre. Bs. As.: Ed. Revista de Occidente, 1969.

5 Empleamos el término según Raúl Bủeno Chávez: "Decimos gestadas pensando en las obras que escriben nuestros autores radicados en otras latitudes...". "Escribir en Hispanoamérica, escribir Hispanoamérica". Rev. de crítica literaria latinoamericana No 23 (1986).

6 Introducimos el térnino sólo en el sentido de provisión, de actualización, de un orden de miradas. La consideración de la estrategia en si excede los límites de esta presentación y amerita un desarrollo diverso. Sin embargo creemos preciso adelantar que en La revolucion en bicicleta sería posible hacet referencia a un efecto crítico de este procedimiento paródico según la propuesta de $M$ Bachtin (Esthetique et theorie du roman. Paris: Gallimard, 1979) en el sentido de poner en cuestión un modo de escritura, plasmado desde ciertas estrategias,a partir de un discurso que insiste en el coloquialismo del sujeto del enunciado, cuyas constantes son el humor y la espontaneidad. Asimnismo podr ia hablarse de cuestionamiento de la noción de héroe y anti-héroe proyectada en el texto-fuente, pero de ningin modo esta critica comprometeria la cosmovisión articulada en Hijo de hombre. 
señaladas incorpora la historia personal de Bartolo vinculada a hechos relevantes de la historia social y política del Paraguay, centralizando el texto el informe sobre la guerra del 47 , estos últimos articulados desde una primera persona. Todo adquiere por ello un ritmo entrecortado y una consecución alógica de las secuencias, caracteristicos de las exposiciones orales. Para no exceder los limites de este trabajo nos interesa focalizar particularmente el procedimiento de inversión de la figura del sujeto del enunciado, quien concentra en sí rasgos del héroe y del anti-héroe de Hijo de hombre, representados por Cristóbal Jara y Miguel Vera respectivamente.

Discursivamente se recupera, al principio de $L a$ revolución en bicicleta la imagen de los pies descalzos para caracterizar a Bartolo Gaite, lo que puede aparecer como poco relevante, pero que releído en el proceso intertextual que señalamos cobra funcionalidad, pues esta marca discursiva que articula a los campesinos de Hijo de hombre y se reitera en todo su desarrollo, remite a un tipo de conexión con el espacio que es manifestación de una situacion definitiva en la historia del colectivo social al cual Bartolo pertenece y del que no puede desvincularse

Las manos regordetas, ajadas, duras como sus pies, casi siempre descalzos, mostraban callos que parecian retazos de una caparazón de tortuga descuartizada. (13)

Los pies descalzos simbolizan su condición: pertenecer al pueblo, formar parte de lo comunitario. Desde esta imagen se instala la figura del hombre paraguayo arraigado a su tierra y a los otros, caracteristica que Bartolo comparte con los revolucionarios del texto de Roa-Cristóbal Jara o los hombres de la picada ${ }^{7}$. En Hijo de hombre el sujeto del enunciado del lineamiento impar, Miguel Vera, un militar de origen humilde como Bartolo, es justamente el personaje marginado por voluntad propia, separado de su grupo por la traición, un intelectual imposibilitado para actuar, el individuo que se contrapone a lo colectivo y que siempre está calzado.

La bicicleta aparece como aquello asociado a Gaite y también a la revolución desde el título mismo; es un elemento definitivo que cobra valor de signo desde su relación sustitutiva con el tren-vagón de Hijo de hombre, el cual se presenta vinculado con la estirpe del héroe y representa la lucha

7 El tratamiento de las imágenes en Hijo de hombre y el sentido que instalan respecto del sistema cultural que se representa en el texto ha sido desarrollado en Mónica Marinone, "El bilingüismo desde la escritura de $A$. Roa Bastos", Revista del CELEHIS - Año I, Nro I, (Primer semestre de 1991): 107-112. 
comunitaria. Ya ha sido señalado por Jean Franco ${ }^{8}$ el proceso de trasposición que nuestros narradores realizan respecto de ciertos objetos articulados en expresiones de otros sistemas culturales y la consiguiente conversión de su significación una vez instaurados en este contexto. Señala entonces, cómo Roa Bastos destruye la connotacion asociada al tren, que no es ya símbolo de progreso, sino de lucha revolucionaria. En el texto de Giardinelli es justamente la bicicleta el objeto sustituto del tren.

Discursivamente el término es introducido a lo largo de todo el texto, modificando su connotación en distintos momentos de la lectura y reinstalándose, de este modo, como signo. Es asi que si recuperamos cierta cronología en el relato, es posible detectar que la bicicleta, durante la niñez, es el "objeto deseado", se convierte en medio de recreación y esparcimiento cuando Gaite está estudiando en Asunción, pero se transforma después en símbolo de la rebelión, la noche de marzo cuando

...recorrimos los puestos de guardia con Chamorto, levantando la tropa, arengando...(40)

Entonces, la repetición jerarquiza el término, especialmente en el primer capitulo del informe, que alude al modo como la revolución fue iniciada. Finalmente la bicicleta el el único medio de transporte que permite a Bartolo, durante su exilio, conectarse con la ciudad y buscar noticias de sus compatriotas. En los capítulos que refieren el presente, el término-signo funciona como soporte a partir del cual se instala al personaje y su hacer.

Creemos que la elección de este objeto no es casual, sino que se corresponde con la significación explícita que el sujeto del enunciado atribuye a la revolución

...porque la revolución, adentro o afuera, en el

triunfo o en la derrola, es un hecho dinámico...(206)

Este planteo entronca asimismo con una de las propuestas esenciales de Hijo de hombre, cuya prevalencia se establece a partir de la organización misma de un relato que va conformándose desde un proceso de intensificación por contraste entre los lineamientos impar y par que introducen la actitud pasiva del sujeto del enunciado y la acción ininterrumpida

8 J. Franco, "La parodia, lo grotesco, lo carnavalesco. Conceptos del personaje en la novela latinoamericana", Punto de vista, Año L Nro l, (1978) 
a la que están asociados los héroes conectados con las insurrecciones ficcionalizadas o referidas. La historia de vida de Bartolo Gaite cobra verdadera significación sólo en función de su hacer respecto de la revolución y de un compromiso permanente con la liberdad de su país, a pesar del fracaso, la cárcel, la tortura o el exilio. El procedimiento de inversión de la figura del militar en La revolución en bicicleta adquiere, entonces, un nuevo sentido, pues instala otra lectura de la relación entre los dos grupos antagónicos del Paraguay - civiles/militares -, desde la recuperación de un acontecimiento atípico y silenciado, como fue el levantamiento de 1947, promovido por estructuras descontentas del ejército y apoyado por todo el pueblo de Concepción.

Sin embargo desde esta perspectiva, la caracterización de Gaite aparecería incompleta si no consideráramos otro elemento vinculado con el desarrollo de la revolución en sí. Discursivamente la radio es el otro término jerarcuizado en el Informe y reemplaza a la bicicleta como nuevo símbolo de la lucha co'sctiva, una vez que ésta se ha puesto en marcha. Se produce con este término una raslación de la significación a medida que se va perfilando su funcionalidad a lo largo del relato sobre la guerra. De ser medio de intercambio de información con ia gente de Asunción (p.62) en la época en que sólo se conspira, pasa a constituirse en soporte que permite llevar adelante el levantamiento. Si bien es cierto qui, desde un primera aproximación, la toma de la radio por parte de los revolucionarios tiene que ver con motivos tácticos y responde a un necesidad de justificar ante la comunidad las acciones iniciadas, es necesario tener presente también el significado que ello supone en función del área cultural bilingüe representada en el texto, en la cual el guaraní y el castellano coexisten como lengua nacional (oral) e idioma nacional (oral y escrito). Desde el planteo que parte de la consideración de la lengua natural como sistema de modelización primario a partir del cual se determina la visión de mundo de un colectivo social, creemos pertinente recuperar ciertas reflexiones metatextuales de Roa Bastos quien alude a "la cultura paraguaya en su totalidad como expresión de una realidad en lento y complejo proceso de transformación (que) es y seguirá siendo por mucho tiempo todavia, una cultura eminentemente oral... El trasfondo o atmósfera (...) está inconscientemente teñido para todos-creo incluso, hasta para los que no hablan guaraní

9 Remitimos a la llamada hipótesis Sapir-Whorf según la cual la lengua detennina la organización socio-cultural y la visión de mundo de una colectividad, así como a lo señalado por $\mathrm{E}$. Benveniste: "...existe un modelo semiótico que la lengua ejerce y del que no se concibe que su principio resida en otra parte que no sea la lengua". Problemas de lingüistica general. Madrid: Siglo XXI, 1978. 
- de la naturaleza oral de esa cultura escindida". ${ }^{10}$ La pertenencia de Bartolo Gaite a su comunidad de origen implica un conocimiento profundo de esta situación. Por ello recurre a la oralidad, para lograr el apoyo del pueblo y no intertumpe nunca la proyección a los otros desde un discurso germinado en la convicción que trabaja con el guarani y consigue movilizar, de este modo, la voluntad colectiva, manifestada discursivamente desde un nosotros gritado en la lengua ancestral

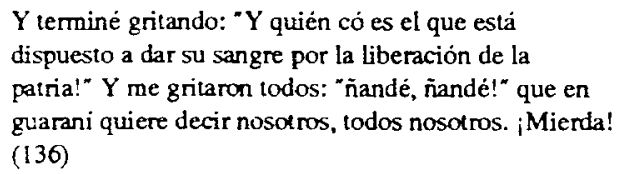

Esto es particularmente significativo y remite al proceso de inversión indicado, pues Gaite proviene de un estrato deslegitimado en el Paraguay, a lo largo de un devastador proceso histórico de formación.

La oralidad se manifiesta aun en la organización del texto que, según señaláramos en principio articula, como en Hijo de hombre, un relato entrecortado $y$ además insiste en marcas discursivas permanentes ${ }^{11}$ que instalan el coloquialismo del sujeto del enunciado, reforzado por reflexiones metatextuales que aluden a su condición de relator. Entonces, la voz de Bartolo Gaite, que es soporte de la rebelión del 47 , vuelve a ser actualizada y superpone el tiempo-espacio referido en la ficción sobre el tiempo-espacio de producción, pero también compromete el de la lectura, desde un discurso que restituye la dimensión plena de un diálogo ${ }^{12}$ en que el lector se vuelve oyente de la historia.

La apelación a una re-lectura de conflictos del pasado aparentemente ya resueltos o cerrados tiene que ver, en ambos textos con la necesidad de transgredir lo institucionalizado desde el código hegemónico. Ya lo ha manifestado reiteradamente Roa "La historia tal cual la conocemos en

10 A. Roa Bastos, "Cultura oral y literabura ausente". Página 12, (26 de enero, 1989).

11 Nos referimos por ejemplo a shifters (en el sentido que Jakobson ha dado a ese térnino, en Ensayos de linguistica general. Barcelona: Seix-Bartal, 1975) de organización del discurso; a uso reiterado de adverbios en mente que funcionan como operadores pragmáticos indicadores de actitud racional ( A M Barrenechea, "Operadores pragmaticos de actitud oracional: los adverbios en 'mente" y otros signos", Estudios lingüisticos y dialectológicos. Bs. As.: Hachette, 1979); a empleo constante de construcciones verbales o particulas que instalan el refuerzo de la aserción, etc.

12 J. Onega. "La literatura latinoameticana en la década del 80", Revista lberoamericana Nro $110-111(1980)$ 
América Latina no es más que una ficción documentalizada" ${ }^{13}$ y existe planteo explícito en La revolución en bicicleta

...una guerra (la de 1865-1870) que deformó nuestra historia y que produjo el enorme trauma de un pueblo al que sólo le enseriaron mentiras. (22)

La intertextualidad como mecanismo a partir del cual planteamos esta aproximación a La revolución en bicicleta permite, por lo expuesto, no sólo recuperar y examinar un tex to-fuente, sino la cosmovisión particular de un sistema cultural y el discurso que la sustenta. El texto de Giardinelli se constituye en un espacio discursivo que transforma ciertos acontecimientos del pasado en signos capaces de ser re-interpretados desde un nuevo contexto de ideas, pero simultáneamente vehiculiza la recuperación de otros signos homólogos desde el enlace con ese texto latente del cual se vuelve receptáculo y continuación. El proceso de inversión de la figura del militar paraguayo que realiza Giardinelli respecto del texto de Roa Bastos es coherente con le recorte de ese fragmento del pasado que fue la guerra del 47 y el procedimicnto resulta acabado pues discursivamente se actualizan rasgos culturales que aparecen como constantes en Hijo de hombre: el arraigo como condición determinante de un compromiso respecto de la lucha por la libertad colectiva desde un hacer continuo, aún lejos de la propia tierra y la oralidad como rasgo que manifiesta la pertenencia al sistema cultural bifronte plasmado en la ficción. Por eso Bartolo Gaite sigue andando en bicicleta en su presente de exiliado y vive buscando y esperando noticias o cartas que cristalicen la lucha del pasado y la posibilidad del regreso, con esa esperanza en el futuro que guía a los compueblerinos de Miguel Vera y que él nunca ha podido compartir

¡Otro día, sí, y eso es lo bueno! (206)

julio - 1991.

CELEHIS-Univ. Nac. de Mar del Plata.

13 Ch.Kupchik, "Una insurrección contra la historia". Entrevista a A Roa Bastos, Crisis, (enero-febrero, 1988) 


\section{RESUMO}

A leitura de La revolición en bicicleta, de Mempo Giardinelli, se filia a um outro texto-signo anterior, Hijo del hombre, de Roa Bastos, ao mesmo tempo em que diagola com o sistema cultural ao desvendar o discurso das lutas pela liberdade coletiva do Paraguai. 